\title{
Student enjoy to learning and broaden their horizons with language at the library in the centre of the school
}

\author{
Harumi Onimaru \\ Meisei Gakuen Elementary School and Meisei Gakuen Junior \& Senior High School \\ 1-1 Sakae-cho, Fuchu-shi, Tokyo 183-0051 \\ Japan \\ harumi.onimaru@stf.meisei.ac.jp \\ 5050haruoni@gmail.com
}

\begin{abstract}
headline
The school library is one of the best environments for learning. Student loves school library and can feel inspired to learning.

I designed the school library at Mesei Junior and Senior High School. It is not an ordinary one. The high ceiling, wide tables, wooden structures, earth-tone colors, and bookshelves that reach the top of the ceiling, truly gives the library a special atmosphere.

There are a total of 12 million books available to the students. In addition, there are 65 different magazine titles and 3 million English books. This library also has e-books, Scholastic Bookflix and Trueflix, as the elementary schools in the United States.

The school library produced all of English extensive reading program. Then the library produced a DVD that features English extensive reading. It was featured on NHK, a cable television program, and in some books. Students also borrow over 20 milion title books in a year.
\end{abstract}

Keywords

O: Order

A: Aurora

S: Social Responsibility

I: Intelligence

S: Solace

\section{Cultivating Independence of Mind Through Library Committee Activities}

\section{Overview}

Is it not possible to change our perception of the school library from the idea that it is "only a place where books are stored" to the idea that it is one "special education classroom" where positive educational activities can be carried out in order to nurture the abilities of library committee members and learn about how to create a meaningful library committee. By considering the school library to be a place where each student can nurture their social skills and 
leadership skills we can develop, together with students, the idea of "cultivating independence of mind through library committee activities." With the changing of the life circumstances of students,

more and more individuals are becoming less skillful at participating in cooperative activities. Also, although library committee members should participate in committee activities out of their own free will, many members are leaving decisions up to others and do not even go to the library. At this time of reorganizing and reforming our school's educational activities, I would herein like to report on practical research I have conducted with the aim of developing students who reflect honestly on their own strengths and weaknesses and strive to become confident adults.

\section{Forward}

In 1923, Meisei Junior and Senior High School was established as a practical school in Fuchu, Tokyo. Currently, our school is a junior and senior high school combined with a student number of 1500. In September of 2004, along with the building of a new school facilities, a new library which has an authoritative and educational atmosphere was built with the aim of becoming a showcase for our Meisei brand. Together with the change of having an all-boys and all-girls school to becoming a coed school, the library committee which consists of 90 members, who have gathered at their own free will, continues to uphold the tradition of this committee.

The library ranked second in the Second L-1 Grand Prix and is now propelling what is called the Tohoku Supportive Action. We are practicing our library education in consideration of the fact that school libraries are directly connected with the public in general and are a part of our society's social educational system.

\section{Purpose of research}

During the period when our school consisted of an all-boys and all-girls school, the library committee in the all-boys school was registered as a part of the student council's activities and in the all-girls school as a "special committee" activity. And there was a separate committee for junior high and senior high so accordingly there were 4 school library committees in all. Then, along with our school becoming coed, our school became a junior high and senior high combined school. With these changes, the organization of committees in the school also had to change.

With the completion of the new school facilities, the new library with a floor space of 660 square meters, became a common meeting place for the whole student body of 1500 students. From the onset, a new coed library committee was set up. While upholding the traditions of each school's library committee, a new coed and junior and senior high school combined library committee was set up aiming to become a self-motivated PDCA cycle activity.

\section{Methods and content of research}

The new library's management system basically followed the management system of the old boy's school because it had the longest history, but it incorporated characteristics of the 
previous 4 schools so as to make a smooth transition to becoming a coed library. We are aiming to making a student-centered library where the students themselves can help with the management of the library.
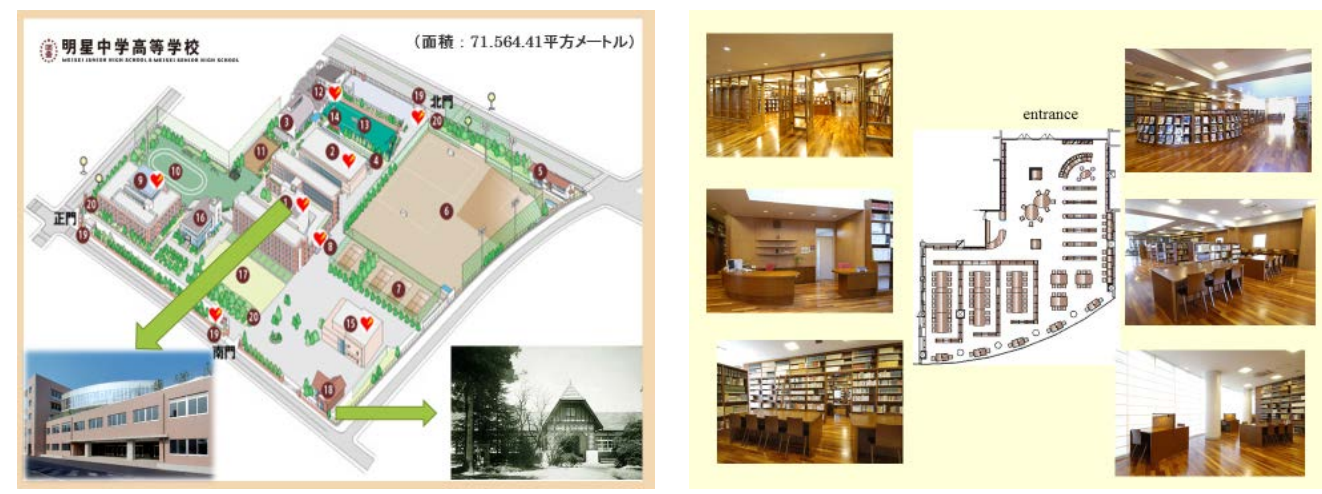

Figure1:Meisei Junior \& Snior High School Library

\section{2-1 The library use system was made into one system}

2-2 In 2005, the boys library planning and management committee set up a "volunteer story reading brigade." This committee appealed to the girl's same committee and together they carried out a joint coed event. Their first volunteer story reading was held at the Meisei Kindergarten which is located on the same campus.
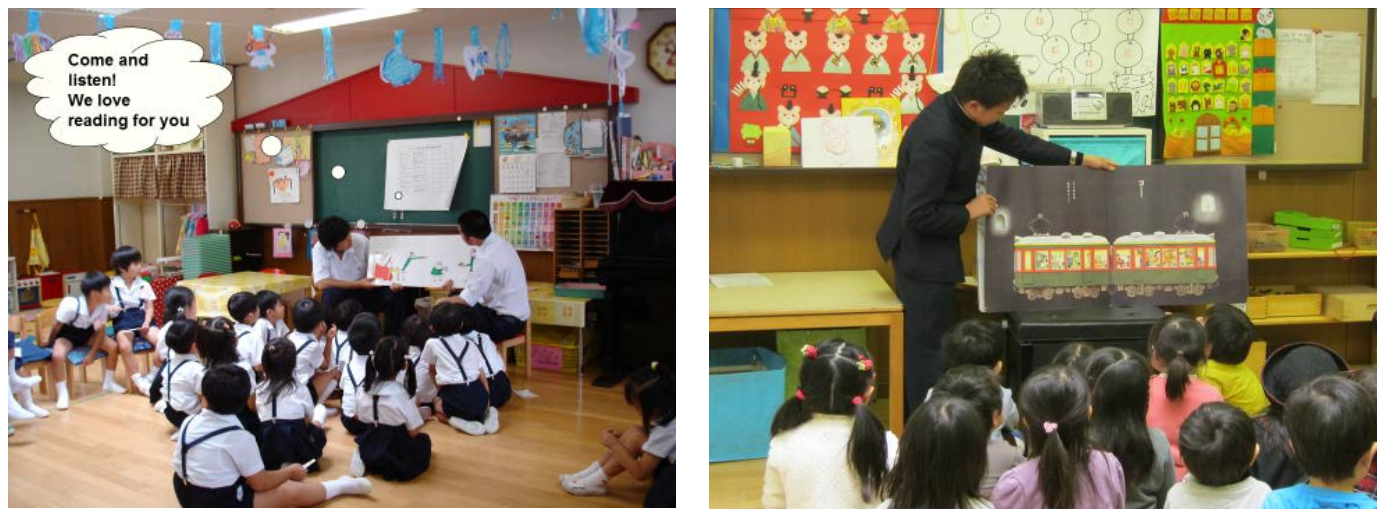

Figure2:School's Library Committee

2-3 In 2008, the all-girls "special library committee" was dissolved and this committee was incorporated into the school's Library Committee, as one committee in the student council. At the student council's annual general meeting, the Library Committee carried out a presentation (hand made by the student's themselves)

2-4 In 2009, the junior high and senior high separate library committees were combined and officially became The Junior and Senior High School Library Committee. In this way the junior and senior high school combined educational activity was initiated.

2-5 In 2011, for the Meisei School Festival, the Library Committee officially registered it's activity as The Library Committee. With all committee members participating, a story reading was held in the library. 

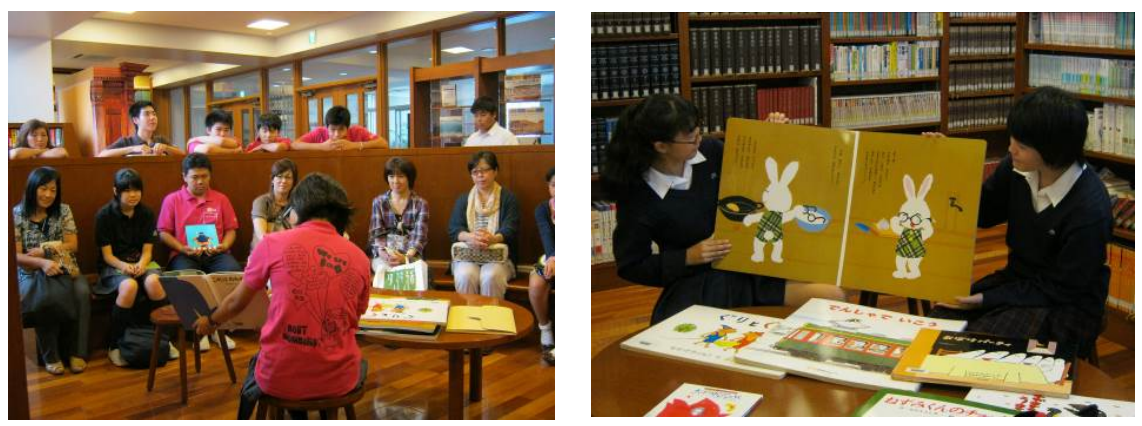

Figure3: A story reading in the library at school festival

2-6 In 2011, we entered the Second L-1 Grand Prix and came in second place. As representatives of our school's Library Committee, members from junior high $1^{\text {st }}$ year to senior high $3^{\text {rd }}$ year made presentations. It was the first time for a student under 10 years of age to participate in a presentation at this contest so this fact gained much attention.

2-7 In 2012, we entered the Second L-1 Grand Prix for the second time and we took first place. We carried out the following two Library Committee cooperative projects; "Shanti Volunteer Association" and "The Great East Japan Earthquake relief work."

As part of the "Run Tohoku! Mobile Library Project" we made and sent wall newspapers to Odate Town Library and Kanamachi Library.

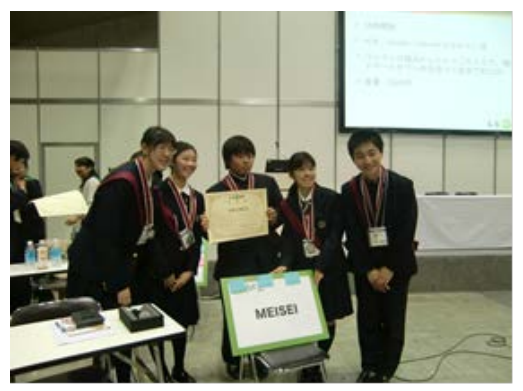

Figure4: "The Great East Japan Earthquake relief work."

2-8 In 2014, for the Meisei School Festival the Library Committee sponsored a panel- lecture by Ms. Kikuchi Kazuko, the photographer who carried out a fixed point observation of Kamaishi City after The Great East Japan Earthquake. The Library Committee started planning for the following year's event.
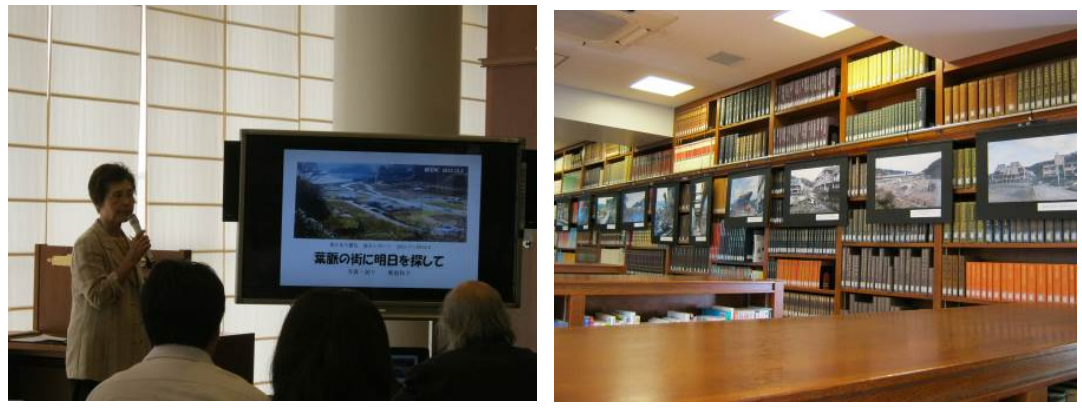

Figure5: a panel- lecture by Ms. Kikuchi Kazuko 
2-9 On July $22^{\text {nd }}$ of 2015 , for the first time ever in Japan, the Library Committee sponsored a workshop titled, "Coloring for Adults." Support from Kawade Shobo Shinsha Publishers and Sakura Color Products Corp. Lecture by Sakura Art Museum curator.

2-10 For the 2015 Meisei School Festival the Library Committee sponsored a "Coloring for Adults" exhibition and workshop.
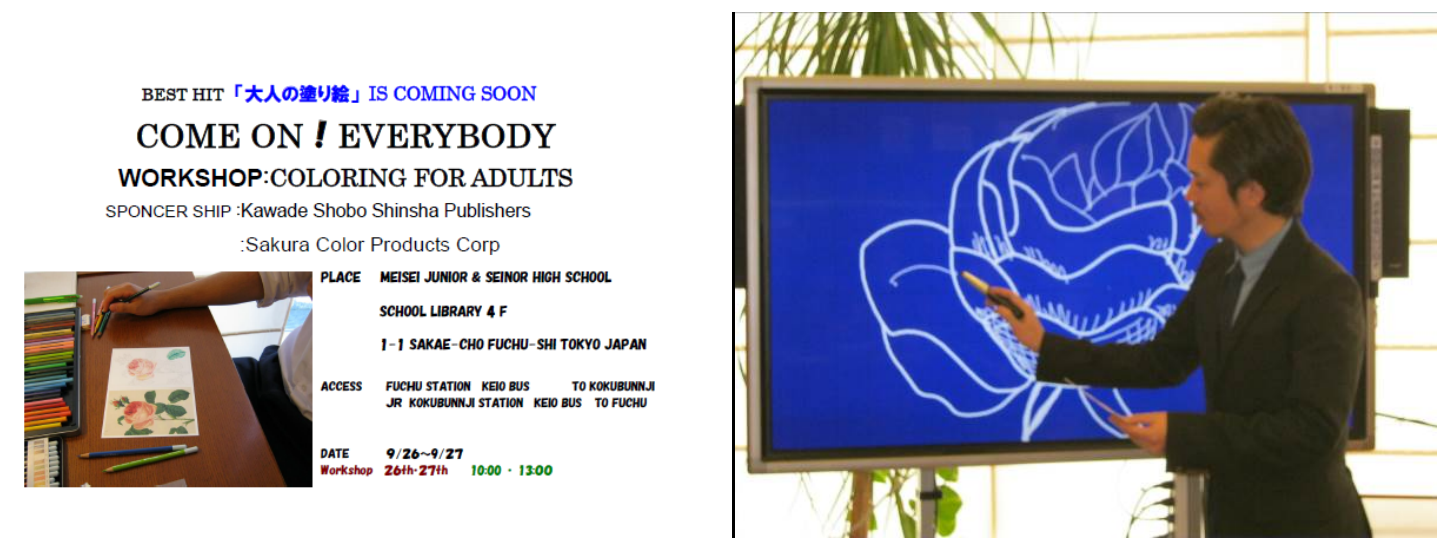

Figure6: "Coloring for Adults" exhibition and workshop

\section{Conclusion}

We have strived to encourage the members of our school's Library Committee to think about what our committee's role should be as part of the Student Council organization. One of the strong points of being a combined junior and senior high is that senior high school students can lead and do joint activities. By working in small groups and meeting often the students have learned to share their ideas openly. They have discussed together about the problems and management methods of our committee and by doing so they have learned how to overcome various problems. The School Library has thus become a place for learning from each other. The students do not arbitrarily choose a leader of the committee but rather through daily activities leadership is developed synergistically and we feel this is what is important. By watching over the active activities of the students, students learn how to move forward a big organization and by doing so they will learn skills they will need in society. They will learn how to express themselves while at the same time learning to respect and nurture the abilities of others and thus they will become global citizens.

In this day and age of a low birth rate, it is at times difficult to attract new library committee members. Changes in student council activities and its organization will of course affect the organization of the School Library Committee. Furthermore, students are now leading very busy lives at school and at home yet we feel it is important to encourage students to develop their own leadership skills and nurture a spirit of wanting to help others. The new age is demanding that changes be made in the field of education. It is important that we communicate with our students and provide them with a space where they can make their abilities come to life. This can be done 
by learning together from our experiences. The school library has a direct connection to society. It is our great wish to nurture students who will be able to contribute to society. However, how well they can do this is greatly affected by the experiences they have during their schooling and the quality of their education. Library education is thus very important and the school library committee organization can play a great role in each student's schooling.

\section{Global Understanding Education Fostered by Library Education}

Establishing an Extensive English Reading Program and Supporting Systems in School Libraries

Overview

From the founding of our school we built a school library with the hope of creating a parallel universe inside the school. To be able to create the "heart" of the school education, affirmative book reading activities of students should be rooted in the aim of "learning a language, cultivating sensitivity, enhancing expressiveness and stimulating creativity." Reading activities have to be something that teaches students how to build strength in themselves so that they can live a meaningful life. Furthermore, reading activities will gain liveliness when the needs and consciousness of students bond together with the needs of the times and thus students can interact and learn from each other. We believe that all school libraries must make efforts to improve the level of global understanding and education in the $21^{\text {st }}$ century with firm faith, propel extensive reading education and consolidate an environment so as to help students' learning/reading activities and global understanding of students. In this article, I will present the activities and practical researches performed by school libraries which are providing educational activities to support their students.

Extensive reading/hearing shadowing in school libraries International education

\section{Forward}

In 1923, Meisei Junior and Senior High School was established as a practical school in Fuchu, Tokyo. Currently, our school is a junior and senior high school combined and the number of students is currently1500. In September of 2014, management software was installed in the library in concert with the union of the two libraries in the school. The united library which has an authoritative and educational atmosphere contains an estimated 200 thousand books. The library, a parallel universe in our school has become many of our students' "oasis." And the library committee which consists of 80 members who have gathered at their own free will continue to uphold the tradition of this committee. The library ranked second in the Second L-1 Grand Prix and is now propelling what is called the Tohoku Supportive Action. We are practicing our library 
education in consideration of the fact that school libraries are directly connected with the public in general and are a part of our society's social educational system.

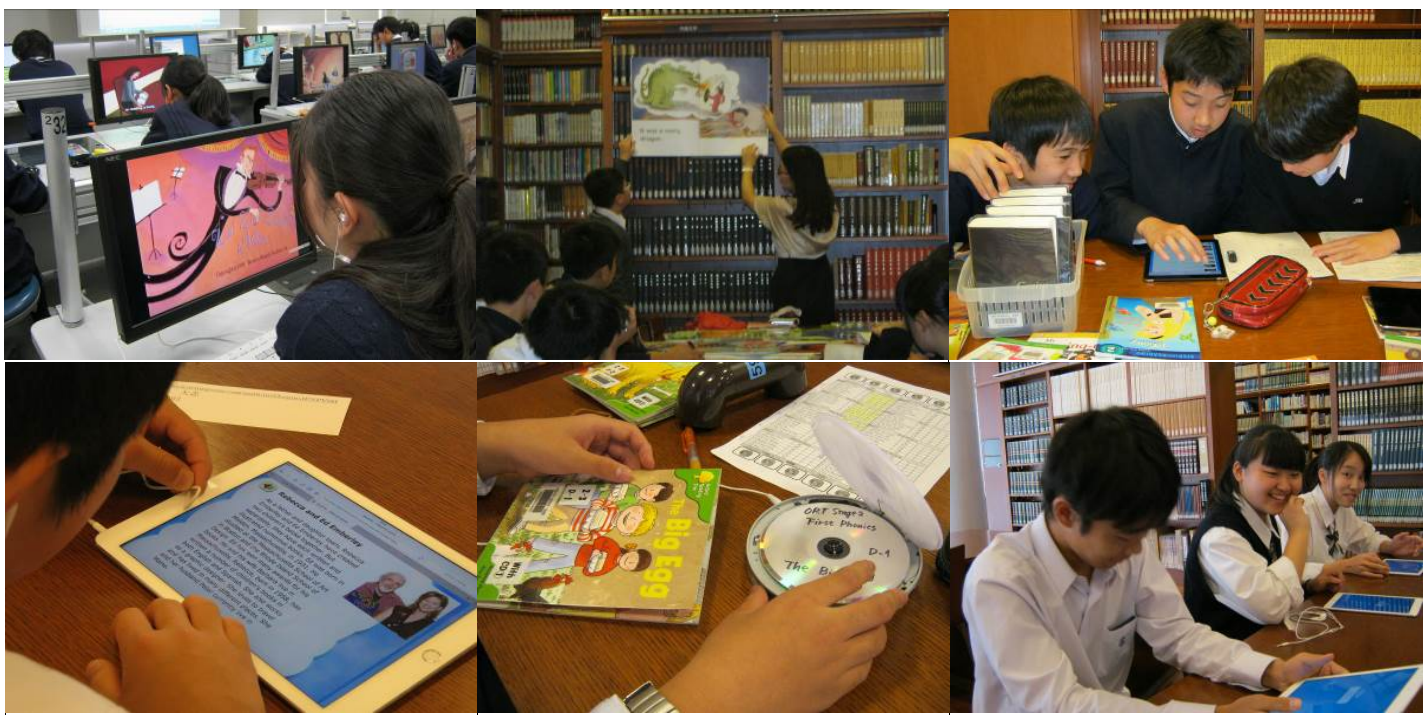

Figure7 : Students enjoy active learning

Young people nowadays are not used to reading. In order to encourage them to read more books, we thought it is necessary to rebuild their reading experiences. Although we are feeling the necessity of encouraging students to read more fairytales, folktales and biographies which have not been popular among young people, we understand that it is normal to have a sense of resistance to reading such books in their period of adolescence. We think that it is important to carry out an extensive English reading program in the phase of major changes of children's reading activities. Students will spend more time on reading in multiple languages and enjoy reading textbooks and picture books of English-speaking countries at their own will. School libraries are now being put to the test, that is, as to whether they are offering students better learning environments and learning activity support. When a school library becomes the "heart" of the school and starts to beat, it will pump out energy to the students.

\section{Purpose of performing research}

To give students who are not used to reading an experience of acknowledging that reading is fun, we feel that offering students a sense of accomplishment of reading an entire book is important. Rewritten simplified books read by children at the reading introduction age in English-speaking countries might provide a fertile reading experience to Japanese children. Famous folktales written by major authors such as Grimm Brothers, Andersen and Shakespeare can become a good introduction to international education. In addition, we thought that reading English books has a function of reminding the students of their experience of reading their first book and will give students a sense of accomplishment.

By preparing lots of textbooks and side-readers published in English-speaking countries, we can meet the diverse needs of our students and they can share the excitement of reading with their 
friends since each of them will read books that they are interested in. Growth of the desire to read leads them to improve their four skills (listening, reading, speaking and writing) and they will recognize the importance of improving these four skills when learning a foreign language. And I think school libraries will be able to lay out the framework of such learning activities. From the perspective of library administration, utilization rate and lending rate will increase and school libraries will rejuvenate by shifting the system of the libraries to a new level from the perspective of users. Students can read foreign books anytime they want and school libraries will become a crucial service in schools as a result of an increase in the utilization rate, lending rate and an interest in reading books.

\section{Method and content of research}

We decided to start an early English extensive reading program from within the classroom. We suggested that we set up a completely new and unique intensive reading program and decided to utilize the school library which has lots of English title books. We considered how we could create a program that would assist the students to the utmost. With the purpose of choosing and increasing the number of English books in the school library, we investigated what kinds of books each English publisher has. We even went to England to explain about the situation of our school library and when a new book series was to be published we stated our preferences and by doing so we were able to build strong connections with various publishers. As a library we looked into getting the authors copyright permission. We also did research as a library into different ways of purchasing English books and also looked into how to file English books in a library and how to update management software so as to keep records of each student's book readings. We researched how to do word counts of each book and how to record this in each book's bibliographic filing so that students can utilize this information in their extensive reading. We did research into how to develop classes which would stimulate the students, for example as part of our extensive reading program we incorporated shadowing very early on and made this a standard procedure.

We looked into how to organize reading materials so that they could be used easily and how to lessen the work load of teachers when an extensive reading program was introduced into the curriculum. We also looked into how to keep records of each student's reading history. (We made a pre reading sheet to be filled out before reading a certain series.) We created a time schedule for the extensive reading program. We researched to learn about the necessity of sound recognition in foreign language acquisition and researched about how to incorporate shadowing. We looked at how input style teaching and output style teaching affected the student's development in foreign language acquisition of the four basic skills. We looked at correlations between the number of books read by students and accumulated word counts with STEP test results. Looking at the needs of each student we continually offered after-school reading advice. We have made it a point to closely observe our students progress and continue to strive to better our school library and extensive reading program. 
TRUE FLIX

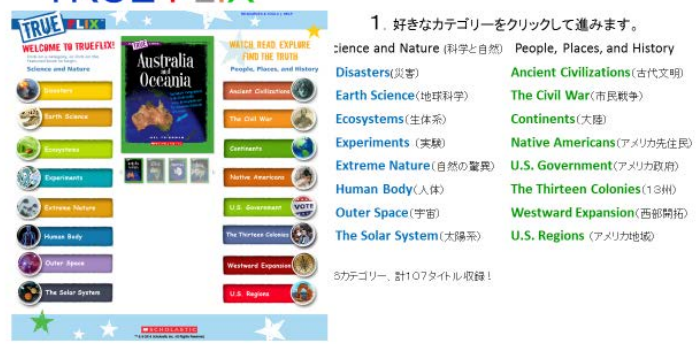

\section{Book FLIX}

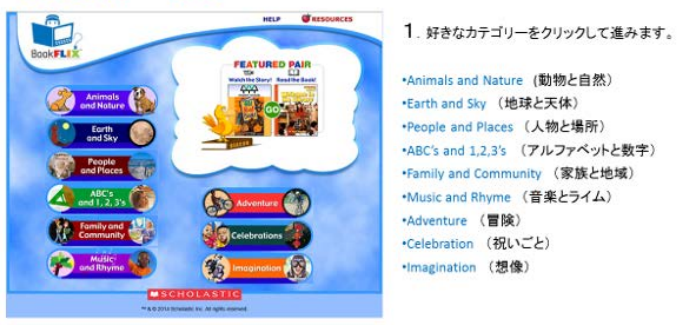

Figure8:egook

\section{Research accomplishments}

With the aim of increasing the library usage rate we conducted 28 hours of classes per week. We have increased the number of English books, the English book count now being 38 thousand books. The borrowed book count has increased and is now over 200 thousand per year. We have students now who have an accumulated word count of over 1 million words. We have signed contacts for copyright usage. The number of students who take the STEP test has increased. We have had authors visits to our school and we have held learning sessions for our students.

Through the use of speaker phones many student's listening skills have advanced.

*assisting in the release of Popcorn ELT Readers (Mary Glasgow Magazines-Scholastic Ltd) *assisting in making of Sunshine Books listening CDs (CTM Co.)

* making of extensive reading, extensive listening DVD for "Part 2, Revolution in English Classes" T\&H Co.

*Introducing of E-books Scholastic Co's Book Flix / True Flix (this is a side-reader textbook which is being used in public elementary schools in the US) We were the first school in Japan to introduce this material thus helping to create a foreign language learning environment in the home.

*the holding of an open public seminar titled, Happy Reading (Supported by the Fuchu Education Board)

*holding of a seminar at Fuchu No.1 Elementary School titled, "Parent and child - Let's enjoy reading English books in the library" 


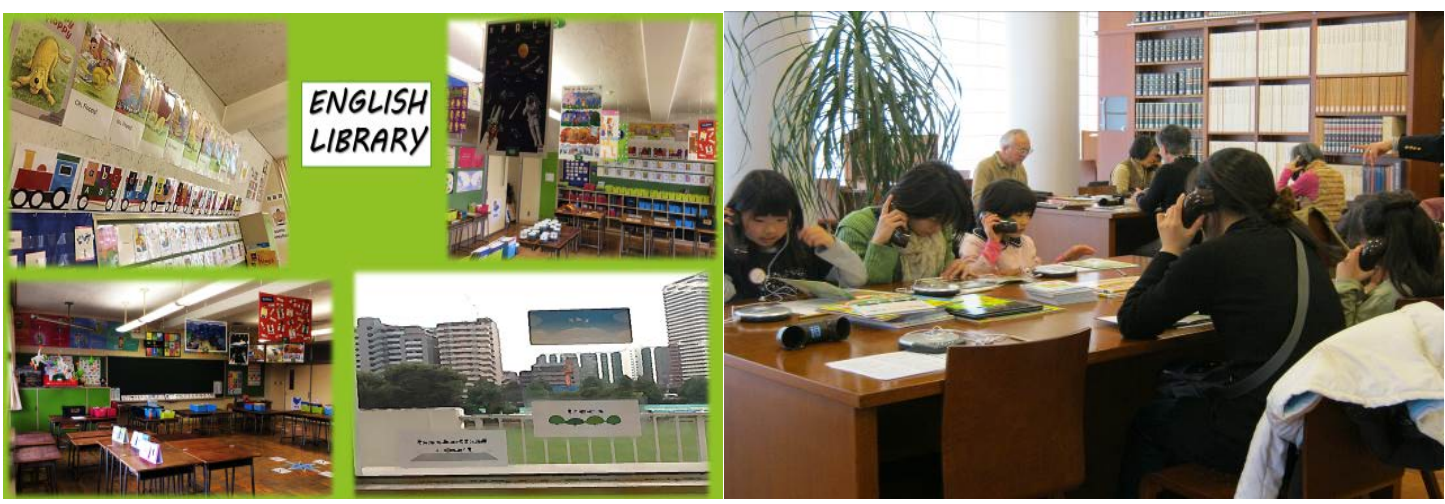

Figure9:Fuchu No.1 Elementary School Library and Open School for Fuchu

\section{Biographical note}

The school library produced all of English extensive reading program. Then the library produced a DVD that features English extensive reading, listening, dictation, and shadowing. This is a unique study program that is found only at Mesei Gakuen Junior and Senior High School. It was featured on NHK, a cable television program, and in some books. Mesei Gakuen Junior and Senior High School students attend an English extensive learning class in the library once a week. There is an after-school program called, Power up TADOKU, that offers extensive English reading to students of all grade levels. The program`s inclusion of students of all ages is a unique model within the traditional Japanese school system. Now English extensive reading class are 43classes in a week at the library. High School students borrow over 20 milion title books of Meisei Gakuen Junior \& Senior High School library in a year. Student loves school library.
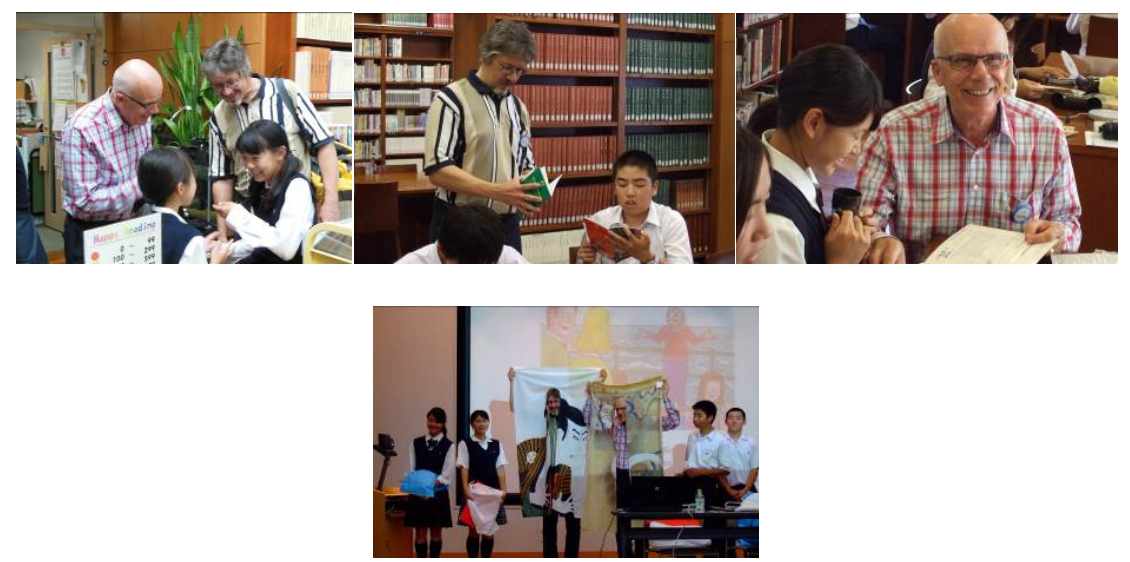

Figure10 : The author are coming, Roderick Hunt and Alex Brychta 